\title{
Effect of Bypass on Overall Performance of Pin-Fin Heat Sinks
}

\author{
W. A. Khan*, J. R. Culham ${ }^{\dagger}$ and M. M. Yovanovich ${ }^{\ddagger}$ \\ Microelectronics Heat Transfer Laboratory \\ Department of Mechanical Engineering \\ University of Waterloo, Waterloo, Ontario, Canada, N2L 3G1
}

\begin{abstract}
One of the most important factors influencing the overall performance of cylindrical pin-fin heat sinks is the bypass phenomenon. Depending upon the total bypass area in comparison to the flow area between pin-fins, a significant portion of the approaching air flow bypasses the heat sink. In this study, the effects of side and top bypass on the hydraulic and thermal performances of a cylindrical pin-fin heat sink will be investigated in laminar forced convection. Theoretical models, based on laws of conservation of mass, momentum and energy, will be developed to predict flow velocity, pressure drop and heat transfer from the heat sink and the bypass regions. These models will help in determining hydraulic and thermal resistances in each region. Both in-line and staggered arrangements are analyzed in this study. Analytical/empirical correlations are used to determine friction factors and heat transfer coefficients in both arrangements. The effects of thermal spreading and joint resistances are neglected in this study.
\end{abstract}

\section{Nomenclature}

$A_{b} \quad$ Area of the base plate $\equiv L \times W_{2}, \mathrm{~m}^{2}$

$A_{f} \quad$ Frontal face area of heat sink, $\mathrm{m}^{2}$

Dimensionless longitudinal pitch $\equiv S_{L} / D$

$b \quad$ Dimensionless transverse pitch $\equiv S_{T} / D$

$C_{1}, C_{2} \quad$ Constants defined in Eq. (20)

$C L_{s} \quad$ Side clearance ratio $\equiv 2 W_{1} / W_{2}$

$C L_{t} \quad$ Top clearance ratio $\equiv H_{2} / H_{1}$

$c \quad$ Dimensionless diagonal pitch $\equiv S_{D} / D$

CPFHS Circular pin-fin heat sinks

$D \quad$ Pin diameter, $\mathrm{m}$

$D_{h} \quad$ Hydraulic diameter, $\mathrm{m}$

$f \quad$ Friction factor

$K \quad$ Correction factor defined in Eq. (10)

$K_{1}, K_{2}, K_{3} \quad$ Constants defined in Eq. (21)

$k \quad$ Thermal conductivity, $\mathrm{W} / \mathrm{m} \cdot \mathrm{K}$

$K_{c}, k_{e} \quad$ Contraction and expansion coefficients in heat sink region

$H \quad$ Height $m$

*Postdoctoral Fellow, Department of Mechanical Engineering, Member AIAA.

$\dagger$ Associate Professor, Director, Microelectronics Heat Transfer Laboratory, Department of Mechanical Engineering.

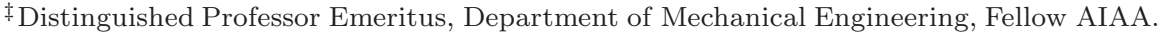




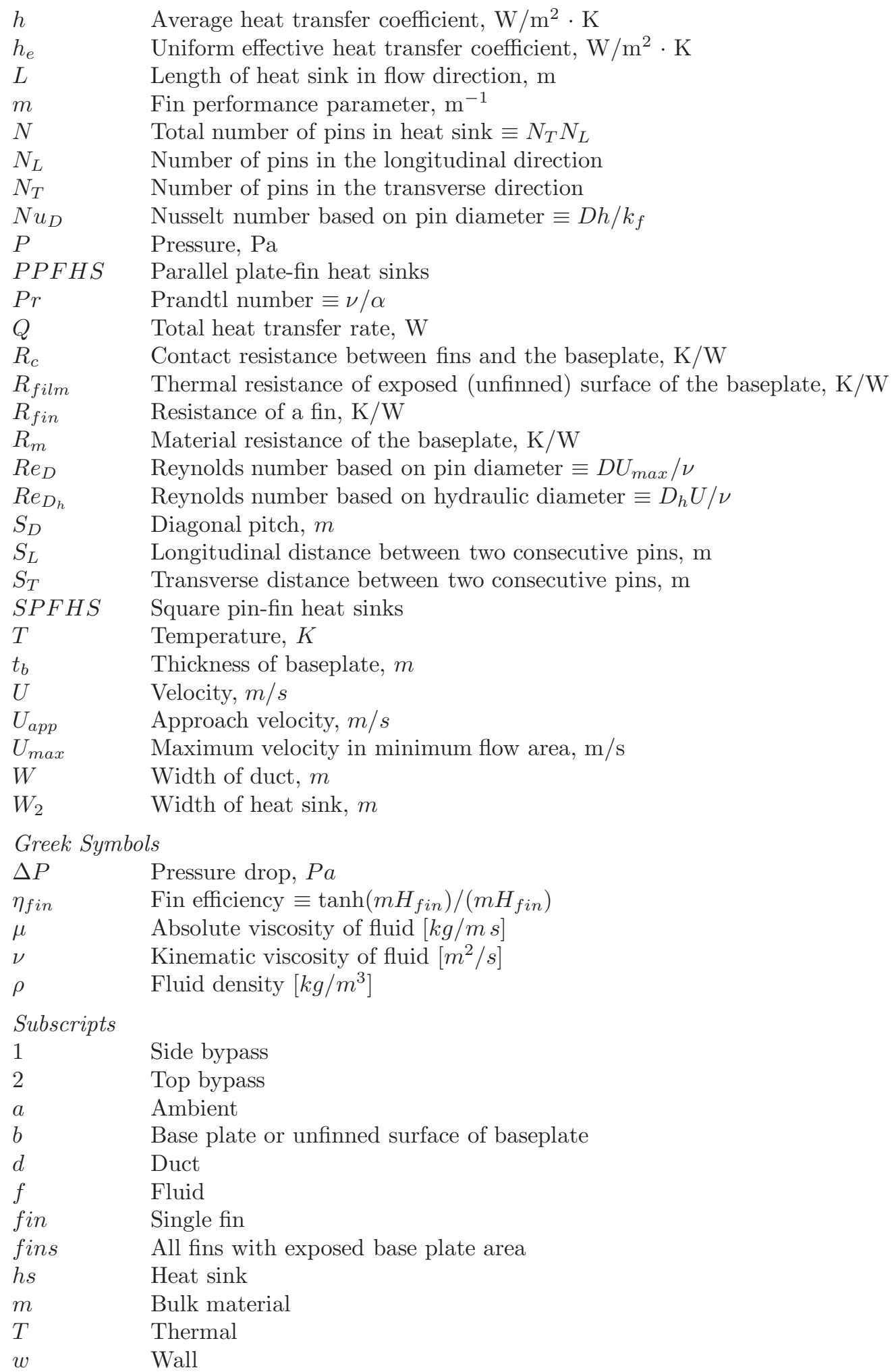




\section{Introduction}

The continuing increase of power densities in microelectronics and the simultaneous drive to reduce the size and weight of electronic products have led to an increased importance of thermal management issues in this industry. A common method for cooling packages is the use of pin-fin heat sinks. These heat sinks provide a large surface area for the dissipation of heat and effectively reduce the thermal resistance of the package. They often take less space and contribute less to the weight and cost of the product. For these reasons, they are widely used in applications where heat loads are substantial and/or space is limited. They are also found to be useful in situations where the direction of the approaching flow is unknown or may change. The majority of these pin-fin heat sinks are mounted on circuit boards where significant clearances are available on the sides and the top. Due to higher resistance for flow through the heat sink, the approaching cooling fluid takes a detour around the heat sink, which always results in a better hydraulic performance but poorer thermal performance. In this paper, the effects of side and top bypass on the overall performance of a pin-fin heat sinks are investigated for in-line and staggered arrangements.

\section{Literature Review}

The effect of flow bypass on the overall performance of plate fin heat sinks has been investigated experimentally $^{1-9}$, numerically ${ }^{10,11}$, and analytically ${ }^{12-14}$. Ortega and his coworkers ${ }^{15-18}$ conducted extensive experiments to study hydraulic and thermal performances of in-line SPFHS with/without top and side bypass. They also developed a two-branch semi-inviscid bypass model to calculate the pressure drop across the heat sinks. They found that side bypass results in higher overall pressure drop compared to top bypass. They also found that the overall heat transfer is governed by the fin flow which is influenced by the top bypass as well as pin pitch. Later on, Shaukatullah et al. ${ }^{19}$ performed experiments on in-line SPFHS for use in low velocity applications and optimized the thermal performance. They kept the design simpler and cheaper.

Rizzi et al. ${ }^{20,21}$ and Jonsson et al. ${ }^{22,23}$ investigated the effects of bypass on heat transfer and pressure drop in CPFHS, SPFHS, and PPFHS experimentally. Rizzi et al. [20,21] developed a number of data reduction parameters and procedures using scaling for heterogeneous media suggested by volume averaging theory. They developed a corelation relating heat transfer performance to Reynolds number and other important characteristic parameters. Jonsson et al. ${ }^{22,23}$ also developed an empirical correlation for different fin designs. Their correlation predicts the Nusselt number and the dimensionless pressure drop and takes into account the influence of duct height, duct width, fin height, fin thickness, and fin-fin spacing. They also developed a physical bypass model for plate fin heat sinks to describe the bypass effect.

Jonsson and Moshfegh ${ }^{24,25}$ developed three-dimensional CFD models of CPFHS in bypass flow. They used Chen-Kim $k-\epsilon$ model in turbulent flow. They studied the influence of increasing fin height in the flow direction, and uneven distribution of the fins in the lengthwise and the spanwise direction. They showed that an increase in the heat transfer coefficient can be achieved by an uneven distribution of the fins in the lengthwise direction, using smaller fin spacing at the trailing edge of the heat sink. They also performed a parametric study and found that the inlet velocity, the fin height, and the fin-to-fin distance have strong influences on the heat transfer coefficient and the pressure drop. Chapman et al. ${ }^{26}$ investigated the effect of air flow bypass characteristics in open duct configuration. They found that the straight fin experiences the lowest amount of flow bypass over the heat sink. For this particular application, where the heat source is localized at the center of the heat sink base plate, the overall thermal resistance of the straight fin was lower than the other two designs mainly due to the combined effect of enhanced lateral conduction along the fins and the lower flow bypass characteristics. 


\section{Analysis}

The front, side and top views of an in-line pin-fin heat sink are shown in Fig. 1. The dimensions of the baseplate are $W_{2} \times L \times t_{b}$, where $W_{2}$ is the width of the entrance, $\mathrm{L}$ is the length measured in the downstream direction and $t_{b}$ is the thickness of the base plate.

The dimensions of the duct are $W \times H$, where $W$ is the width and $H$ is the height of the duct. The dimensions of the side bypass are $W_{1} \times H_{1}$, where as the dimensions of the top bypass are $W \times H_{2}$. Flow in side and top bypass regions is assumed as inviscid flow. The pin-fins can be arranged in an in-line or staggered manner. Each pin fin has diameter D and height $\mathrm{H}$. The dimensionless longitudinal and transverse pitches are $a=S_{L} / D$ and $b=S_{T} / D$. The source of heat is applied to the bottom of the heat sink. Heat is applied uniformly over the full area of the base plate. The flow is assumed to be laminar, steady, and two dimensional. The duct velocity of the fluid is $U_{d}$ and the ambient temperature is $T_{a}$. There is no leakage of fluid from the top or sides. The wall temperature of the pin is $T_{w}\left(>T_{a}\right)$ and the baseplate temperature is $T_{b}$. The side and top clearance ratios are defined as

$$
\begin{aligned}
& C L_{s}=\frac{2 W_{1}}{W_{2}} \\
& C L_{t}=\frac{H_{2}}{H_{1}}
\end{aligned}
$$

\section{A. Hydraulic Resistance}

When the heat sink is not fully shrouded, some air flows between pin-fins and the remaining air bypasses the heat sink. Due to the bypass effect, the heat transfer and pressure drop across the heat sink decreases. The amount of flow in the heat sink and bypass regions depends on their hydraulic resistance or pressure drop. It affects the overall performance of the heat sink. Higher hydraulic resistance causes less airflow through the heat sink channel, attaining a lower convection heat transfer rate between the fins and the surrounding air and increasing fin thermal resistance. Ortega and his group ${ }^{15-19}$ found from experiments that in most cases the flow begins to split 10 to $20 \mathrm{~mm}$ upstream of the heat sink. Keeping this fact in mind, it is assumed that the flow splits at position 2 and starts to mix at position 4. The pressure drop in the side bypass, top bypass and heat sink regions between positions 2

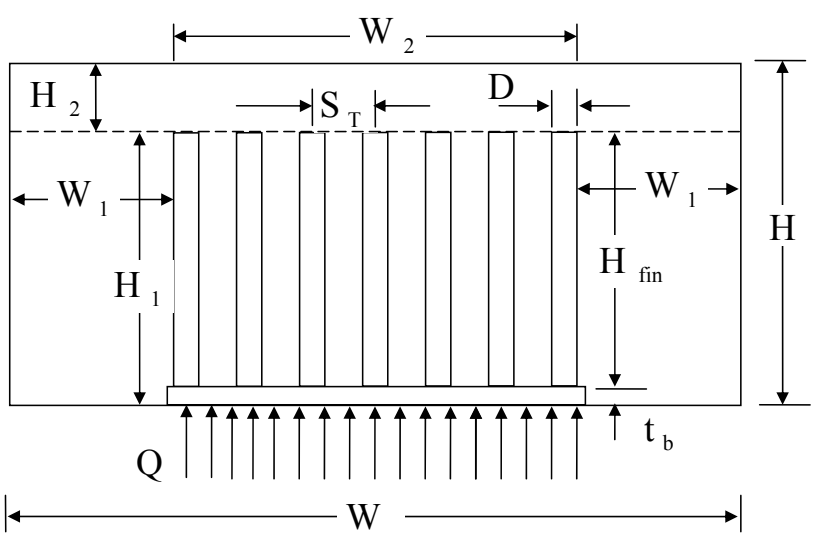

(a) Front View

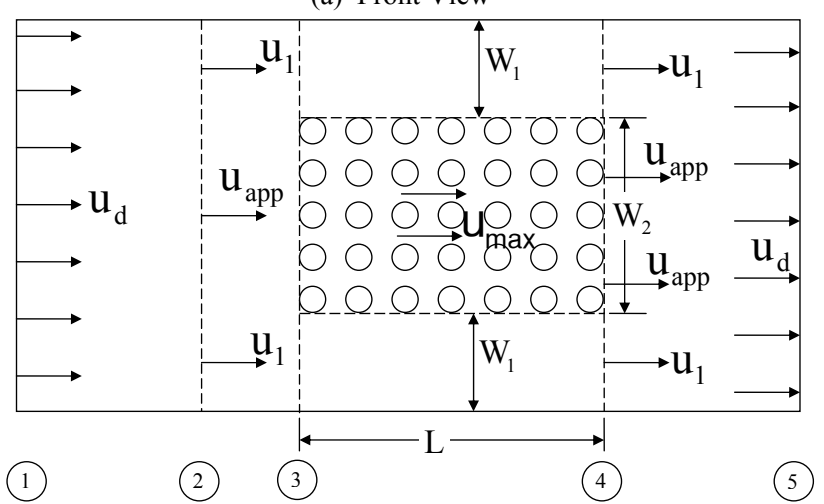

(b) Top View

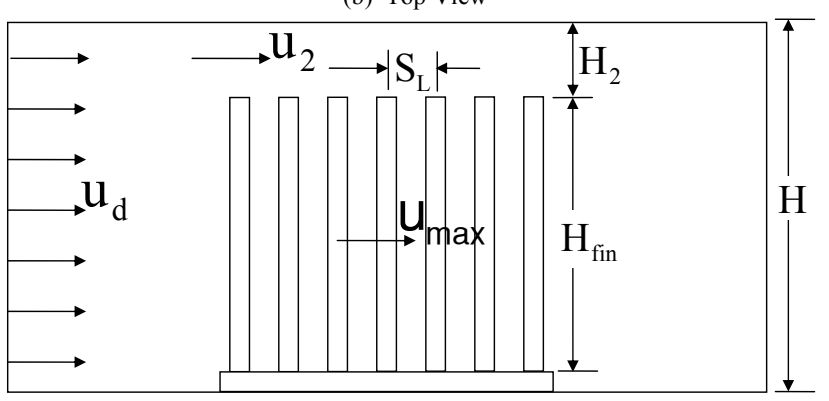

(c) Side View

Figure 1. Front, Top, and Side Views of In-Line Pin-Fin Heat Sinks. 
and 4 (Fig. 2) can be written as:

$$
\left.\begin{array}{rl}
\Delta P_{1} & =\left(\frac{1}{2} \rho U_{1}^{2}\right) f_{1}\left(L / D_{h 1}\right) \\
\Delta P_{2} & =\left(\frac{1}{2} \rho U_{2}^{2}\right) f_{2}\left(L / D_{h 2}\right) \\
\Delta P_{h s} & =\left(\frac{1}{2} \rho U_{\text {max }}^{2}\right)\left[K_{c}+K_{e}+N_{L} f_{3}\right]
\end{array}\right\}
$$

where $f_{1}$ and $f_{2}$ are the friction factors in the side and top bypass regions and are given by

$$
f_{1}=\frac{24}{R e_{D h_{1}}} \quad \text { and } \quad f_{2}=\frac{24}{R e_{D h_{2}}}
$$

with

$$
\begin{array}{lll}
D h_{1}=\frac{4 W_{1} H_{1}}{2 W_{1}+H_{1}} & \text { and } & D h_{2}=\frac{2 W H_{2}}{W+H_{2}} \\
R e_{D h_{1}}=\frac{U_{1} D h_{1}}{\nu} & \text { and } & R e_{D h_{2}}=\frac{U_{2} D h_{2}}{\nu}
\end{array}
$$

For a heat sink, $K_{c}$ and $K_{e}$ are the abrupt contraction and abrupt expansion coefficients respectively, $f_{3}$ is the friction factor, and $N_{L}$ is the number of pins in the longitudinal direction. The coefficients of abrupt contraction and expansion have been established graphically by Kays ${ }^{27}$ for a number of geometries. The following correlations are derived from those graphs:

$$
\begin{aligned}
& K_{c}=-0.0311 \sigma^{2}-0.3722 \sigma+1.0676 \\
& K_{e}=0.9301 \sigma^{2}-2.5746 \sigma+0.973
\end{aligned}
$$

with

$$
\sigma=\frac{b-1}{b}
$$

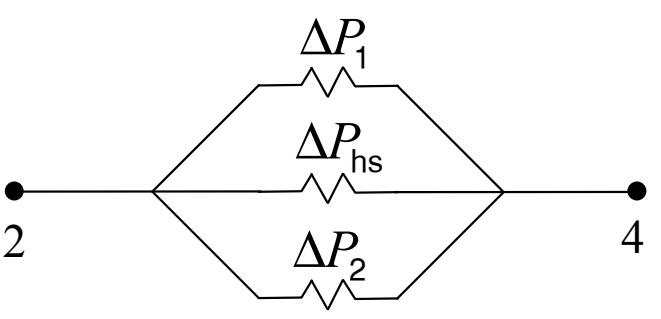

Figure 2. Hydraulic Resistances in Side Bypass, Top Bypass, and Heat Sink Regions.

Žukauskas and Ulinskas ${ }^{28}$ collected data, from a variety of sources, about friction factors for the flow in-line and staggered arrangements having many rows and plotted them in the form $E u / K$ versus $R e_{D}$, where $K$ is a parameter accounting for geometry. They fitted these plots by inverse power series relationships and recommended several correlations depending on the value of $a$ and on the Reynolds number range. They also fitted and recommended correlations for the correction factors for the pressure drop with small number of rows. Khan et al. ${ }^{29}$ combined all the recommended correlations for pressure drop and their correction factors separately and developed single correlations for the friction factors and correction factors for each arrangement. These correlations can be used for any pitch and Reynolds number in the laminar flow range. They are

$$
f_{3}= \begin{cases}K\left[0.233+45.78 /(b-1)^{1.1} R e_{D}\right] & \text { In-Line arrays } \\
K\left[378.6 / b^{13.1 / b}\right] / R e_{D}^{0.68 / b^{1.29}} & \text { Staggered arrays }\end{cases}
$$

where $K$ is a correction factor depending upon the flow geometry and arrangement of the pins. It is given by:

$$
K= \begin{cases}1.009\left(\frac{b-1}{a-1}\right)^{1.09 / R e_{D}^{0.0553}} & \text { In-Line arrays } \\
1.175\left(a / b R e_{D}^{0.3124}\right)+0.5 R e_{D}^{0.0807} & \text { Staggered arrays }\end{cases}
$$




\section{B. Average Velocities in Side Bypass, Top Bypass and Heat Sink Regions}

From the law of mass conservation between 1 and 2 (Fig.1 b),

$$
U_{d} A_{d}=U_{1} A_{1}+U_{2} A_{2}+U_{a p p} A_{f}
$$

where $A_{d}, A_{1}, A_{2}$, and $A_{f}$ are the areas of the duct, side bypass, top bypass, and the frontal face area of the heat sink and can be written as

$$
\begin{aligned}
A_{d} & =W H \\
A_{1} & =2 W_{1} H_{1} \\
A_{2} & =W H_{2} \\
A_{f} & =W_{2} H_{f i n}
\end{aligned}
$$

The force balance between 1 and 4, in side bypass, top bypass and heat sink regions (Fig. 1 b), gives

$$
\begin{aligned}
P_{1}+\frac{1}{2} \rho U_{d}^{2} & =P_{4}+\frac{1}{2} \rho U_{1}^{2}+\Delta P_{1} & & \text { Side bypass } \\
P_{1}+\frac{1}{2} \rho U_{d}^{2} & =P_{4}+\frac{1}{2} \rho U_{2}^{2}+\Delta P_{2} & & \text { Top bypass } \\
P_{1}+\frac{1}{2} \rho U_{d}^{2} & =P_{4}+\frac{1}{2} \rho U_{a p p}^{2}+\Delta P_{h s} & & \text { Heat sink }
\end{aligned}
$$

where $U_{1}, U_{2}$ and $U_{a p p}$ are the average velocities in the side, top and frontal regions of the heat sink respectively. The average maximum velocity in the heat sink region can be determined using continuity between 2 and 3 .

$$
U_{\text {max }}=\sigma_{3} U_{\text {app }} \quad \text { with } \quad \sigma_{3}=\frac{S_{T}}{S_{T}-D}
$$

From Eq. (16), we get

$$
\frac{1}{2} \rho U_{1}^{2}\left(1+K_{1}\right)=\frac{1}{2} \rho U_{2}^{2}\left(1+K_{2}\right)=\frac{1}{2} \rho U_{a p p}^{2}\left(1+\sigma_{3}^{2} K_{3}\right)
$$

Simplifying, we get

$$
U_{a p p}=C_{1} U_{1}=C_{2} U_{2}
$$

where

$$
C_{1}=\sqrt{\frac{1+K_{1}}{1+\sigma_{3}^{2} K_{3}}} \quad \text { and } \quad C_{2}=\sqrt{\frac{1+K_{2}}{1+\sigma_{3}^{2} K_{3}}}
$$

with

$$
K_{1}=f_{1} \frac{L}{D h_{1}} \quad K_{2}=f_{2} \frac{L}{D h_{2}} \quad K_{3}=f_{3}\left(K_{c}+K_{e}+f_{3} N_{L}\right)
$$

From Eqs. (11) and (18), we get the average velocities in side bypass, top bypass and, and frontal regions of the heat sink.

$$
\begin{aligned}
U_{1} & =\frac{C_{2} U_{d}}{a_{1} C_{2}+a_{2} C_{1}+a_{f} C_{1} C_{2}} \\
U_{2} & =\frac{C_{1} U_{d}}{a_{1} C_{2}+a_{2} C_{1}+a_{f} C_{1} C_{2}} \\
U_{a p p} & =\frac{C_{1} C_{2} U_{d}}{a_{1} C_{2}+a_{2} C_{1}+a_{f} C_{1} C_{2}}
\end{aligned}
$$

where

$$
\begin{gathered}
a_{1}=\frac{A_{1}}{A_{d}} \quad a_{2}=\frac{A_{2}}{A_{d}} \quad a_{f}=\frac{A_{f}}{A_{d}} \\
6 \text { of } 13
\end{gathered}
$$




\section{Thermal Resistance}

The thermal resistance of a heat sink is a combination of different resistances (Fig. 3). Neglecting thermal joint and spreading resistances, the total thermal resistance of the heat sink can be defined as:

$$
R_{t h}=\frac{1}{\frac{N}{R_{c}+R_{f i n}}+\frac{1}{R_{f i l m}}}
$$

where the thermal resistance of the fin $R_{f i n}$ is in series with $R_{c}$ and parallel with $R_{f i l m}$ and can be written as:

$$
R_{f i n}=\frac{1}{(h A \eta)_{f i n}}
$$

with

$$
\begin{aligned}
\eta_{f i n} & =\frac{\tanh \left(m H_{f i n}\right)}{m H_{f i n}} \\
m & =\sqrt{\frac{4 h_{f i n}}{k D}} \\
A_{f i n} & =\pi D H_{f i n}+\frac{\pi}{4} D^{2}
\end{aligned}
$$

Khan ${ }^{30}$ determined analytically the heat transfer coefficient for the the fins and is given by

$$
h_{f i n}=C_{3} \frac{k_{f}}{D} \operatorname{Re}_{D}^{1 / 2} \operatorname{Pr}^{1 / 3}
$$

where $R e_{D}$ is the Reynolds number based on the pin diameter $D$ and the mean velocity in the minimum free cross section between two rows, $U_{\max }$, for both types of arrangements and is defined as

$$
R e_{D}=\frac{D U_{\max }}{\nu}
$$

with

$$
U_{\max }=\max \left\{\frac{\mathcal{S}_{T}}{\mathcal{S}_{T}-1} U_{a p p}, \frac{\mathcal{S}_{T}}{\mathcal{S}_{D}-1} U_{a p p}\right\}
$$
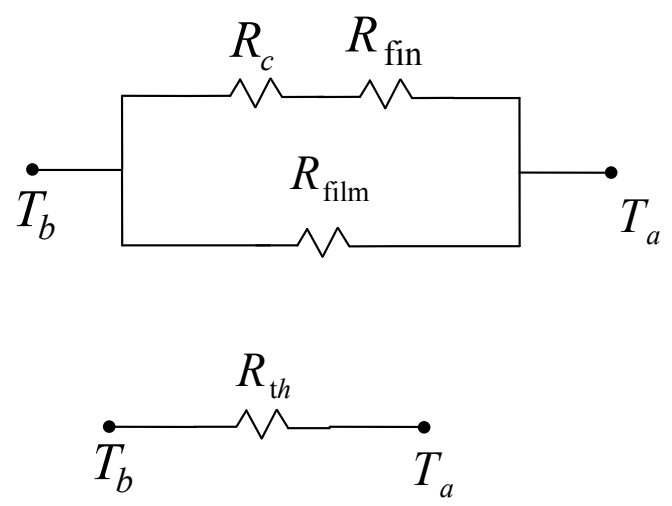

Figure 3. Thermal Resistance of Heat Sink.

where $U_{a p p}$ is the approach velocity, $\mathcal{S}_{L}$ and $\mathcal{S}_{T}$ are the dimensionless longitudinal and transverse pitches, and $\mathcal{S}_{D}=\sqrt{\mathcal{S}_{L}^{2}+\left(\mathcal{S}_{T} / 2\right)^{2}}$ is the dimensionless diagonal pitch in the case of a staggered arrangement. The constant $C_{3}$ in Eq. (12) depends on the geometry of the heat sink and is given by

$$
C_{3}= \begin{cases}{\left[0.2+\exp \left(-0.55 \mathcal{S}_{L}\right)\right] \mathcal{S}_{T}{ }^{0.285} \mathcal{S}_{L}{ }^{0.212}} & \text { In-Line arrangement } \\ \frac{0.61 \mathcal{S}_{T}^{0.091} \mathcal{S}_{L}{ }^{0.053}}{\left[1-2 \exp \left(-1.09 \mathcal{S}_{L}\right)\right]} & \text { Staggered arrangement }\end{cases}
$$

The film resistance, $R_{f i l m}$ is the thermal resistance of the exposed surface of the baseplate, and can be written as

$$
\begin{gathered}
R_{f i l m}=\frac{1}{h_{b}\left(L W_{2}-N \frac{\pi D^{2}}{4}\right)} \\
7 \text { of } 13
\end{gathered}
$$


where $h_{b}$ is the heat transfer coefficient of the base plate, deternmied analytically by Khan ${ }^{30}$

$$
h_{b}=0.75 \frac{k_{f} / D}{\sqrt{N_{L} \mathcal{S}_{L}}} \operatorname{Re}_{D}^{1 / 2} \operatorname{Pr}^{1 / 3}
$$

When the pin-fins are machined as an integral part of the baseplate, there is no thermal contact resistance at their base. However, when pin-fins are manufactured separately and are attached to the baseplate by a metallurgical or adhesive joint or are forced into slots machined on the baseplate, thermal contact resistance, $R_{c}$, can adversely influence the thermal performance of the heat sink. This resistance depends upon the attachment methods involving an adhesive or bonding agent as well as the contact area of the fins, $A_{c}$ with the baseplate, and is written as:

$$
R_{c}=\frac{1}{(h A)_{c}}
$$

where $A_{c}=N \frac{\pi D^{2}}{4}$ is the total contact area of the fins and $h_{c}$ is the thermal contact conductance that ranges typically from $10^{4}$ (metallurgical joint) to $10^{10}$ (perfect joint).

\section{Case Studies and Discussion}

The parameters given in Table 1 are used as the default case to determine the thermal and hydraulic resistances for both in-line and staggered pin-fin heat sinks. The air properties are evaluated at the ambient temperature.

Table 1. Assumed Parameter Values Used to Determine Performance of Heat Sinks

\begin{tabular}{lc}
\hline Quantity & Parameter Values \\
\hline Footprint, $\left(\mathrm{mm}^{2}\right)$ & $50 \times 50$ \\
Source Dimensions, $\left(\mathrm{mm}^{2}\right)$ & $50 \times 50$ \\
Baseplate Thickness, $(\mathrm{mm})$ & 2 \\
Pin Diameter, $(\mathrm{mm})$ & 1.5 \\
Overall Height of Heat Sink, $(\mathrm{mm})$ & 50 \\
Duct Flow Rate, $\left(\mathrm{m}^{3} / \mathrm{s}\right)$ & 0.01 \\
Thermal Conductivity of Solid, $(\mathrm{W} / \mathrm{m} \cdot \mathrm{K})$ & 210 \\
Thermal Conductivity of Fluid, $(\mathrm{W} / \mathrm{m} \cdot \mathrm{K})$ & 0.026 \\
Thermal Contact Conductance,$\left(\mathrm{W} / \mathrm{m}^{2} \cdot \mathrm{K}\right)$ & $10^{4}$ \\
Density of Fluid, $\left(\mathrm{kg} / \mathrm{m}^{3}\right)$ & 1.1614 \\
Specific Heat of Fluid, $(\mathrm{J} / \mathrm{kg} \cdot \mathrm{K})$ & 1007 \\
Kinematic Viscosity, $\left(\mathrm{m}^{2} / \mathrm{s}\right)$ & $1.58 \times 10^{-5}$ \\
Prandtl Number & 0.71 \\
Heat Load, $(\mathrm{W})$ & 10 \\
Ambient Temperature, $\left({ }^{0} \mathrm{C}\right)$ & 27 \\
\hline
\end{tabular}


The effect of top clearance ratio $C L_{t}$ on the average velocity in the top bypass area $U_{2}$, the approach velocity just in front of the heat sink $U_{a p p}$ and the maximum velocity in the heat sink region $U_{\max }$ is shown in Fig. 4. When there is no top clearance, the velocity in the top bypass area $U_{2}$, whereas $U_{\text {app }}$ and $U_{\max }$ are maximum. As $C L_{t}$ increases upto $1 \%$ of the total height of the heat sink, the average velocity in the top bypass region increases sharply and then decreases monotonically. The approach velocity and the maximum velocity in the heat sink decrease with the increase in $C L_{t}$. The same performance behavior was observed with side bypass only.

The maximum velocity in the heat sink is compared in Fig. 5 for both in-line and staggered arrangements in the absence of side bypass. It is observed that $U_{\max }$ is maximum in both arrangements when the top clearance ratio is zero and decreases with the increase in $C L_{t}$. In-line arrangement shows higher $U_{\max }$ and it increases with the increasing $C L_{t}$.

Figure 6 shows the comparison of pressure drop in the heat sink for both in-line and staggered arrangements. For a fully shrouded heat sink (i.e., $C L_{s}=0$ and $C L_{t}=0$ ), the pressure drop is maximum. As expected, pressure drop in the heat sink decreases with an increase in the top clearance ratio since the effective resistance for the flow decreases. The same behavior was noticed with side bypass only. The staggered arrangement shows higher pressure drop in the heat sink for any $C L_{t}$ and the difference between pressure drops in the two arrangements decreases with an increase in $C L_{t}$.

Figure 7 shows the variation of thermal resistance with the top clearance ratio for both in-line and staggered arrangements. In this case, the side clearance ratio is assumed to be zero. As expected, the thermal performance of in-line pin-fin heat sinks is lower than the staggered pin-fin heat sinks for the same material. Note that for $C L_{s}=0$ and $C L_{t}=0$, the entire flow goes through the heat sink and the total thermal resistance of the heat sink is minimum. Thus, the thermal resistance is a direct measure of the deterioration of the thermal performance due to the presence of side and top bypass regions around the heat sink. However, with both side and top clearance ratios, the thermal performance decreases further. This effect is shown in Fig. 8 for an in-line arrangement. The effect of side clearance ratio on the thermal performance is found to be much more pronounced than top clearance ratio only.

The thermal resistance and the total pressure drop for the heat sink are plotted as a function of the top clearance ratio $C L_{t}$ in Fig. 9 for both in-line and staggered arrangements. It is observed that $R_{t h}$ increases and $\Delta P$ decreases with an increase in $C L_{t}$ in both arrangements. It is not possible to get the highest performance (thermal or hydraulic) at the same time. If a higher thermal performance (minimum $R_{t h}$ ) is required, then we have to pay the cost of higher pressure drop

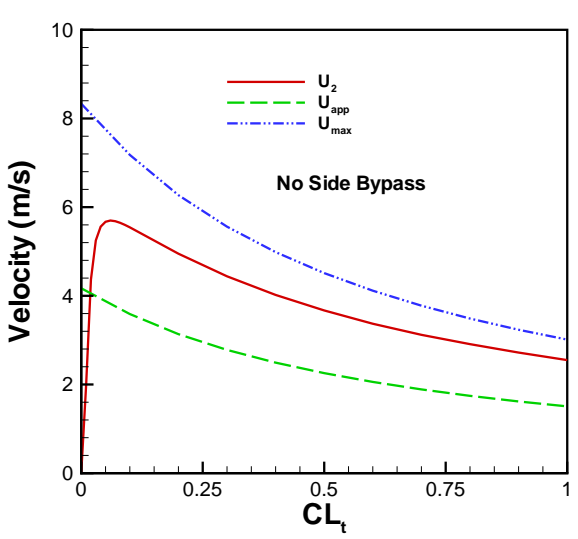

Figure 4. Effect of Top Bypass on Average Velocities.

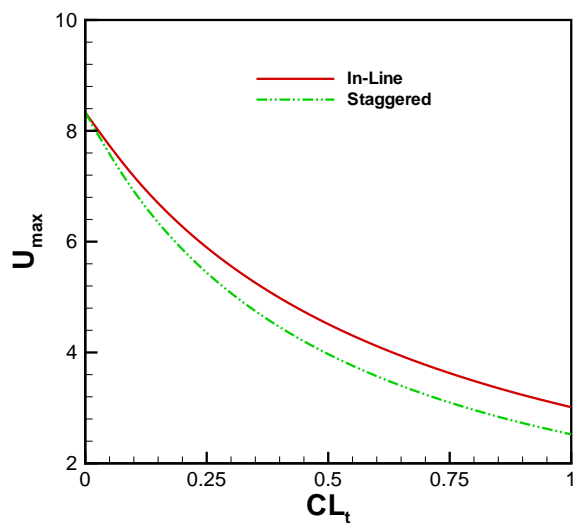

Figure 5. Comparison of $U_{\max }$ for In-Line and Staggered Arrangements.

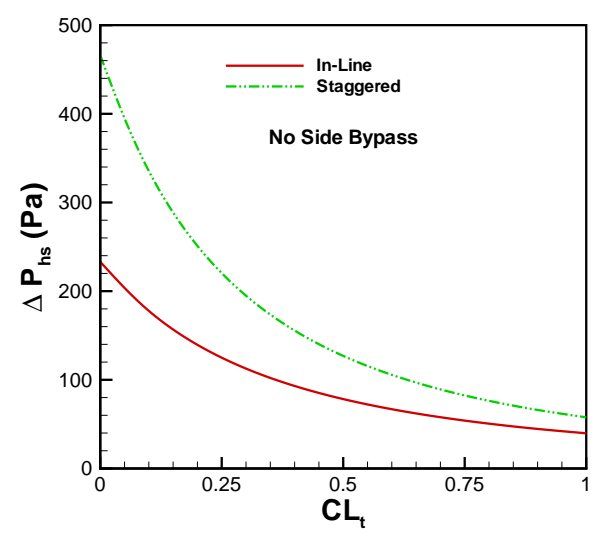

Figure 6. Effect of $\mathrm{CL}_{t}$ on $\Delta \mathrm{P}_{\mathrm{hs}}$ for In-Line and Staggered Arrangements. 
(in terms of pumping power) and if we are looking for minimum pressure drop, then we have to pay for higher $R_{t h}$. In an optimal heat sink, there is a trade-off between these two resistances. It can be seen easily, in Fig. 9, that the staggered arrangement has lower $R_{t h}$ but requires higher $\Delta P$. However, the point of intersection of $R_{t h}$ and $\Delta P$ gives the lower top clearance ratio for an in-line arrangement. It shows that lower top clearance ratios give better overall performance in an inline arrangement.

\section{Conclusions}

The effect of side and top bypass on the overall performance of cylindrical pin-fin heat sinks is investigated in this study. Theoretical models, based on the laws of conservation of mass, momentum and energy, are developed to predict average flow velocity, pressure drop and heat transfer from the heat sink and the bypass regions. Both in-line and staggered arrangements are analyzed in this study. It is shown that an in-line arrangement gives higher thermal resistance but lower pressure drop across the heat sink. Results show that the side and top clearance ratios significantly reduce the pressure drop and heat transfer from heat sinks and as a result the overall performance of heat sinks decreases. Therefore, the effect of bypass on the heat sink performance should be investigated for the effective removal of heat dissipated by the chips.

\section{Acknowledgments}

The authors gratefully acknowledge the financial support of Natural Sciences and Engineering Research Council of Canada and the Center for Microelectronics Assembly and Packaging.

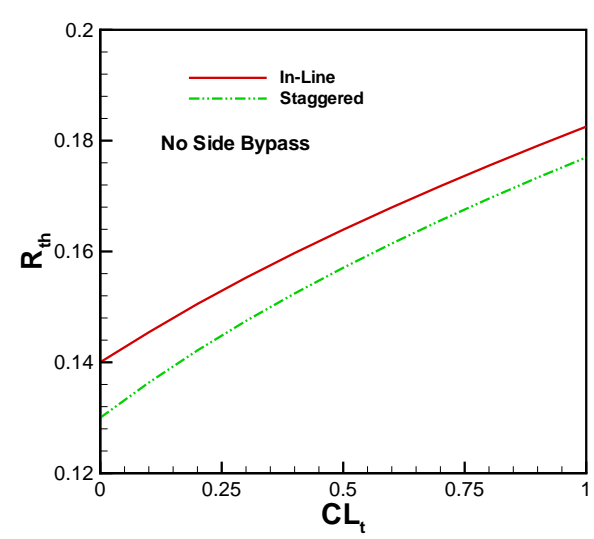

Figure 7. Effect of Top Bypass on Thermal Resistance.

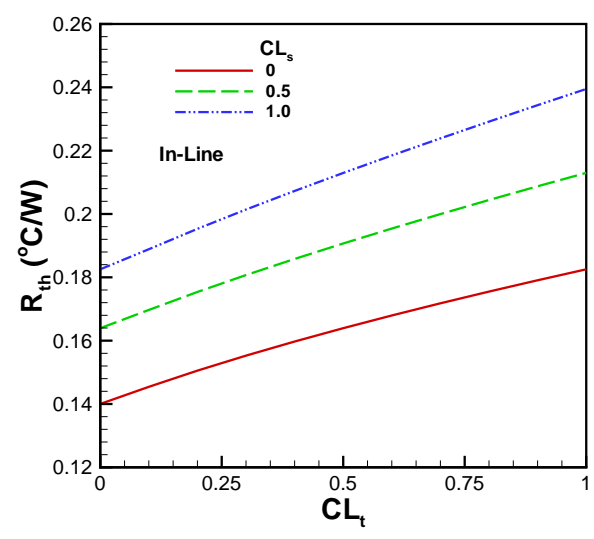

Figure 8. Effect of Side and Top Bypass on Thermal Resistance.

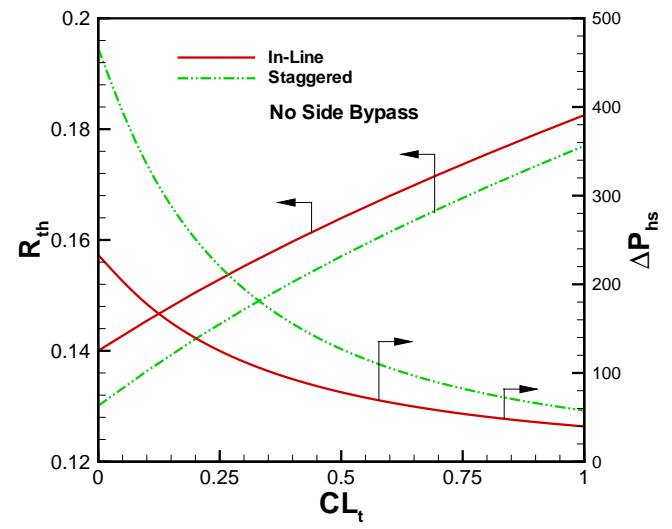

Figure 9. Variation of $R_{\text {th }}$ and $\Delta P$ as a Function of $\mathrm{CL}_{t}$ for In-Line and Staggered Arrangements.

10 of 13 


\section{References}

1. Sparrow, E. M., Beckey, T. J., Pressure Drop Characteristics for a Longitudinal Fin Array With Tip Clearance," Journal of Heat Transfer, Vol. 103, No. 2, pp. 393-395, 1981.

2. Sparrow, E. M., Baliga, B. R., Patankar, S. V., "Forced Convection Heat Transfer From a Shrouded Fin Array With and Without Tip Clearance," Journal of Heat Transfer, Vol. 100, No. 4, pp. 572-579, 1978.

3. Sparrow, E. M., and Kadle, D. S., "Effect of Tip-to-Shroud Clearance on Turbulent Heat Transfer from a Shrouded, Longitudinal Fin Array," Journal of Heat Transfer, Vol. 108, No. 3, pp. 519-524, 1986.

4. Lau, K. S., Mahajan, R. L., "Effects of Tip Clearance and Fin Density on the Performance of Heat Sinks for VLSI Packages," IEEE Transactions on Components, Hybrids and Manufacturing Technology, Vol. 12, No. 4, pp. 757-765, 1989.

5. Lee, R. S., Huang, H. C., Chen, W. Y., "Thermal Characteristic Study of Extruded-Type Heat Sinks in Considering Air Flow Bypass Phenomenon," Proceedings - IEEE Semiconductor Thermal and Temperature Measurement Symposium, pp. 95-102, 1990.

6. Wirtz, R.A., Chen, W., "Longitudinal Fin Heat Sink Performance in Arrays of Low-Profile Electronic Packages," Proceedings of the ASME International Electronics Packaging Conference, Sep 29-Oct 2, 1993, Binghamton, NY, USA, pp. 809-817, 1993.

7. Butterbaugh, M.A., and Kang, S.S., "Effect of Airflow Bypass on the Performance of Heat Sinks in Electronic Cooling," Proceedings of the International Intersociety Electronic Packaging Conference -INTERpack'95. Part 2 (of 2), Mar 26-30, Maui, HI, USA, 1995, pp. 843-848, 1995.

8. dos Reis, E., Altemani, Carlos A.C., "Design of Heat Sinks and Planar Spreaders with Airflow Bypass," Pacific RIM/ASME International Intersociety Electronics Photonic Packaging Conference 'Advances in Electronic Packaging 1999', Jun 13-Jun 19 1999, Maui, HI, USA, Vol. 26-1, pp. 477-484, 1999.

9. Leonard, W., Teertstra, P., Culham, J.R., and Zaghol, A., "Characterization of Heat Sink Flow Bypass in Plate Fin Heat Sinks," ASME International Mechanical Engineering Congress and Exposition, Nov 17-22 2002, New Orleans, LA, United States, Vol. 372, No. 5, pp. 189-196, 2002.

10. Wang, M.P., Wu, T.Y., Horng, J.T., Lee, C.Y., and Hung, Y.H., "Fluid Flow Characteristics for Partially-Confined Compact Plain-Plate-Fin Heat Sinks," ASME Summer Heat Transfer Conference, HT 2005, Jul 17-22 2005, San Francisco, CA, United States, Vol. 4, pp. 687-694, 2005.

11. Narasimhan, S., Bar-Cohen, A., "Compact Modeling of Unshrouded Plate Fin Heat Sinks," International Electronic Packaging Technical Conference and Exhibition, Jul 6-11, 2003, Haui, HI, United States, Vol. 1, pp. 543-550, 2003.

12. Radmehr, A., Kelkar, K. M., Kelly, P., Patankar, S. V., Kang, S. S., " Analysis of the Effect of Bypass on the Performance of Heat Sinks Using Flow Network Modeling (FNM)," 15th Annual IEEE Semiconductor Thermal Measurement and Management Symposium, Mar 9-Mar 11 1999, San Diego, CA, USA, pp. 42-47, 1999.

13. Barrett, A. V., and Obinelo, I. F., "Characterization of Longitudinal Fin Heat Sink Thermal Performance and Flow Bypass Effects Through CFD Methods," IEEE 13th Annual Semiconductor Thermal Measurement \& Management Symposium, Jan 28-30, Austin, TX, USA, pp. 158-164, 1997.

14. Sata, Y., Iwasaki, H., Ishizuka, M., "Development of Prediction Technique for Cooling Performance of Finned Heat Sink in Uniform Flow," IEEE Transactions on Components, Packaging, and Manufacturing Technology Part A, Vol. 20, No. 2, pp. 160-166, , 1997.

11 of 13

American Institute of Aeronautics and Astronautics 
15. Lei, N. and Ortega, A., "Experimental hydraulic characterization of pin fin heat sinks with top and side bypass," Ninth Intersociety Conference on Thermal and Thermomechanical Phenomena in Electronic Systems, Jun 1-4 2004, Las Vegas, NV, United States, Vol. 1, pp. 418-428, 2004.

16. Urdaneta, M., Ortega, A., Westphal, R. V., "Experiments and Modeling of the Hydraulic Resistance of In-Line Square Pin Fin Heat Sinks with Top Bypass Flow," Advances in Electronic Packaging, International Electronic Packaging Technical Conference and Exhibition, Jul 6-11 2003, Maui, HI, United States, Vol. 2, pp. 587-596, 2003.

17. Urdaneta, M. and Ortega, A., "Experiments and Modeling of the Thermal Resistance of In-Line Square Pin-Fin Heat Sinks with Top Bypass flow," Advances in Electronic Packaging, International Electronic Packaging Technical Conference and Exhibition, Jul 6-11 2003, Maui, HI, United States, Vol. 2, 2003, pp. 597-604.

18. Dogruoz, M. B., Urdaneta, M., Ortega, A., "Experiments and Modeling of the Heat Transfer of In-Line Square Pin-Fin heat Sinks with Top Bypass Flow," American Society of Mechanical Engineers, Heat Transfer Division, ASME International Mechanical Engineering Congress and Exposition, Nov 17-22 2002, New Orleans, LA, United States, Vol. 372, No. 7, 2002, pp. 195-206.

19. Shaukatullah, H., Storr, W. R., Hansen, B. J., and Gaynes, M. A., "Design and Optimization of Pin Fin Heat Sinks for Low Velocity Applications," IEEE Transactions on Components, Packaging, and Manufacturing Technology, Part A, Vol. 19, No. 4, pp. 486-494, 1996.

20. Rizzi, M., Catton, I., "An Experimental Study of Pin Fin Heat Sinks and Determination of End Wall Heat Transfer," Proceedings of the ASME Summer Heat Transfer Conference, Jul 21-23 2003, Las Vegas, NV, United States, Vol. 2003, pp. 445-452

21. Rizzi, M., Canino, M., Hu, K., Jones, S., Travkin, V., and Catton, I., "Experimental Investigation of Pin Fin Heat Sink Effectiveness," Proceedings of the National Heat Transfer Conference, Ananheim, CA, United States, Jun 10-12, Vol. 2, pp. 1235-1243, 2001.

22. Jonsson, H., Moshfegh, B., "Modeling of the Thermal and Hydraulic Performance of Plate Fin, Strip Fin, and Pin Fin Heat Sinks - Influence of Flow Bypass," IEEE Transactions on Components and Packaging Technologies, Vol. 24, No. 2, pp. 142-149, , 2001.

23. Jonsson, H. and Moshfegh, B., "Modeling of the Thermal and Hydraulic Performance of Plate Fin, Strip Fin, and Pin Fin Heat Sinks - Influence of Flow Bypass," 7th Intersociety Conference on Thermal and Thermomechanical Phenomena in Electronic Systems-ITherm 2000, May 23-May 26 2000, Las Vegas, NV, USA, Vol. 1, pp. 185-192, , 2000.

24. Jonsson, H. and Moshfegh, B., "Enhancement of the Cooling Performance of Circular Pin Fin Heat Sinks Under Flow Bypass Conditions," Thermomechanical Phenomena in Electronic Systems, 8th Intersociety Conference on Thermal and Thermommechanical phenomena in Electronic Systems, May 30-Jun 1 2002, San Diego, CA, United States, 2002, pp. 425-432.

25. Jonsson, H. and Moshfegh, B., "CFD Modeling of the Cooling Performance of Pin Fin Heat Sinks Under Bypass Flow Conditions," Advances in Electronic Packaging, Pacific Rim/International, Intersociety Electronic Packaging Technical/Business Conference and Exhibition, Jul 8-13 2001, Kauai, Hi, United States, Vol. 1, 2001, pp. 393-403.

26. Chapman, C. L., Lee, S., and Schmidt, B. L., "Thermal performance of an Elliptical Pin Fin Heat Sink," Proceedings of the 10th IEEE Semiconductor Thermal Measurement and Management Symposium, Feb 1-3, 1994, San Jose, CA, USA, pp. 24-31, 1994. 
27. Kays, W. M., "Loss Coefficients for Abrupt Changes in Flow Cross Section With Low Reynolds Number Flow in Single and Multiple Tube Systems," Transactions of ASME, November, pp. 1067-1074, 1950.

28. Žukauskas, A. and Ulinskas, R., "Single-Phase Fluid Flow: Banks of Plain and Finned Tubes," HEDH, Heat Exchanger Design Handbook, Chapter 2.2.4, Washington Hemisphere Publishing, 1983.

29. Khan, W. A., Culham, J. R., and Yovanovich, M. M., "Modeling of Pin-Fin Heat Sinks for Electronic Packaging," presented at SEMI-THERM 21, Semiconductor Thermal Measurement and Management Symposium, San Jose, CA, USA, March 15 -17, 2005. Also accepted for publication in IEEE Transactions on Components and Packaging Technologies.

30. Khan, W. A., 2004, "Modeling of Fluid Flow and Heat Transfer for Optimization of Pin-Fin Heat Sinks," Ph. D. Thesis, Department of Mechanical Engineering, University of Waterloo, Canada. 